\title{
Gold-Silver Catalysts: Ruling Factors for Establishing Synergism
}

\author{
Marta Stucchi, ${ }^{[a]}$ Andrea Jouve, ${ }^{[a]}$ Alberto Villa, ${ }^{[a]}$ Gergely Nagy, ${ }^{[b]}$ Miklòs Németh ${ }^{[b]}$ \\ Claudio Evangelisti, ${ }^{[\mathrm{c}]}$ Rodolfo Zanella, ${ }^{[\mathrm{d}]}$ and Laura Prati*[a]
}

\begin{abstract}
DPU and SOL immobilisation have been used to prepare $1 \%$ AuAg/TiO ${ }_{2}$ with internal ratio $1: 1$ and $4: 1$ which have been studied as fresh, calcined in air at $300^{\circ} \mathrm{C}$ and reduced at $550^{\circ} \mathrm{C}$ in $\mathrm{H}_{2}$. TEM-EDS, XPS, UV-Vis and CO-DRIFT allowed to characterize the samples in terms of particle size, particle composition, exposure and oxidation state of metals. Correlating these characteristics to the catalytic behaviour we concluded that only Au-rich catalysts show synergistic effect, silver in bimetallic
\end{abstract}

\section{Introduction}

Gold catalysts proved to be a sustainable choice for the selective oxidation of alcohols. ${ }^{[1]}$ Catalytic oxidation reactions allow converting bio-renewable feedstock to higher-valued chemicals and they are at the base of the current production of petrochemicals from not-exhaustible sources. ${ }^{[2]}$ Glycerol is a highly functionalized bio-renewable molecule, coming as byproduct from the production of biodiesel. ${ }^{[3]}$ The selective transformation of glycerol allows obtaining many valued products, so much that glycerol is expected to become one of the major renewable building block chemicals thus consisting a platform molecule. Glycerol can be oxidized to glyceric acid, tartronic acid, glycolic acid, oxalic acid and other important chemical intermediates (Figure 1), hence its conversion opens significant new markets in polymers, ethers and other fine

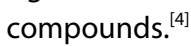

Many papers already reported that gold particle size is crucially important in determining the activity and the selectivity in glycerol oxidation, being particles in the range 2

[a] Dr. M. Stucchi, A. Jouve, Dr. A. Villa, Prof. L. Prati Università degli Studi di Milano

Dipartimento di Chimica

via C. Golgi 19, 20133 Milano, (Italy)

E-mail: Laura.Prati@unimi.it

[b] G. Nagy, M. Németh

Centre for Energy Research

Surface Chemistry and Catalysis Department

PO Box 49, H-1525 Budapest, (Hungary)

[c] Dr. C. Evangelisti

CNR, Istituto di Scienze e Tecnologie Molecolari (ISTM)

via G. Fantoli 16/15, 20138 Milano (Italy)

[d] Prof. R. Zanella

Instituto de Ciencias Aplicadas y Tecnología

Universidad Nacional Autónoma de México

Circuito Exterior S/N, C. U., 04510, Mexico City (Mexico)

Supporting information for this article is available on the WWW under https://doi.org/10.1002/cctc.201900591

This manuscript is part of the Special Issue dedicated to the Women of Catalysis. systems appears more resistant to oxidation than in monometallic one, thermal treatment enhances the SMSI thus producing (regardless to the post-treatment) almost the same amount of $\mathrm{Au}^{\delta+}$ and also $\mathrm{Ag}^{\delta+}$. Catalysts prepared by DPU (calcined in air or reduced in $\mathrm{H}_{2}$ ) are more active than $\mathrm{SOL}$ (fresh or calcined) probably due to the higher presence of gold at the surface.

$5 \mathrm{~nm}$ more active than $10-30 \mathrm{~nm}$, which in turn are more selective toward glyceric acid. ${ }^{[5,6]}$ However, monometallic Au suffers from deactivation due to nanoparticle sintering or to the formation of carbonyl compounds irreversibly adsorbed on the active sites of the catalysts. ${ }^{[7-10]}$ Many papers reported the synergistic effect of bimetallic structures in different catalytic reactions, such as $\mathrm{PtCu}$ alloys, ${ }^{[11,12]}$ or PtPd alloys ${ }^{[13]}$ compared to monometallic Pt. As well as Y. Wang et al. ${ }^{[14]}$ reported a synergistic effect in a bimetallic structure of $\mathrm{ZnO}$ and $\mathrm{TiO}_{2}$. The use of gold-based bimetallic catalysts have shown to overcome a lot of these problems, enhancing activity, stability, and selectivity. ${ }^{[15]}$ In particular, Ag was studied as a second metal for improving the catalyst activity and resistance. ${ }^{[16]}$ Recent studies by $\mathrm{Mou}^{[16]}$ and Zanella ${ }^{[17]}$ proved that in $\mathrm{CO}$ oxidation AuAg particles are more active than monometallic ones, thus showing synergistic effect. The addition of one metal to another can produce a large diversity in the structure and morphology of NPs. The nanoparticle composition has a strong influence on the catalytic activity, but also its structure such as disordered/ ordered, segregated, or core-shell, plays a role modulating the material features and its behaviour. ${ }^{[17]}$ Although it is clear that the extent of alloying in bimetallic systems influences catalytic activity and selectivity, understanding the origin of this effect is still lacking. ${ }^{[18]}$ Theoretical studies ${ }^{[19]}$ investigated the segregation of $\mathrm{Ag}$ in $\mathrm{Au}-\mathrm{Ag} \mathrm{NPs}$, reporting that segregation is composition, size and temperature dependent. In agreement with this, Slater et al. ${ }^{[20]}$ studied $\mathrm{Ag}-\mathrm{Au}$ nanoparticles with controlled compositions and structures through the combination of STEM imaging with EDX spectroscopy, showing that nanoparticle surface segregation inverts from Au-rich to Ag-rich as $\mathrm{Au}$ content increases. ${ }^{[20]}$ On the other hand, segregation in bimetallic particles can be also influenced by the synthetic route and by post-treatments. Zanella et al. ${ }^{[17]}$ studied $\mathrm{Au}-\mathrm{Ag}$ bimetallic catalysts supported on $\mathrm{TiO}_{2}$ by sequential deposition-precipitation method, with $4 \mathrm{wt} . \%$ gold loading and various amounts of silver proving the synergistic effect between gold and silver. It was also shown that catalyst activation 


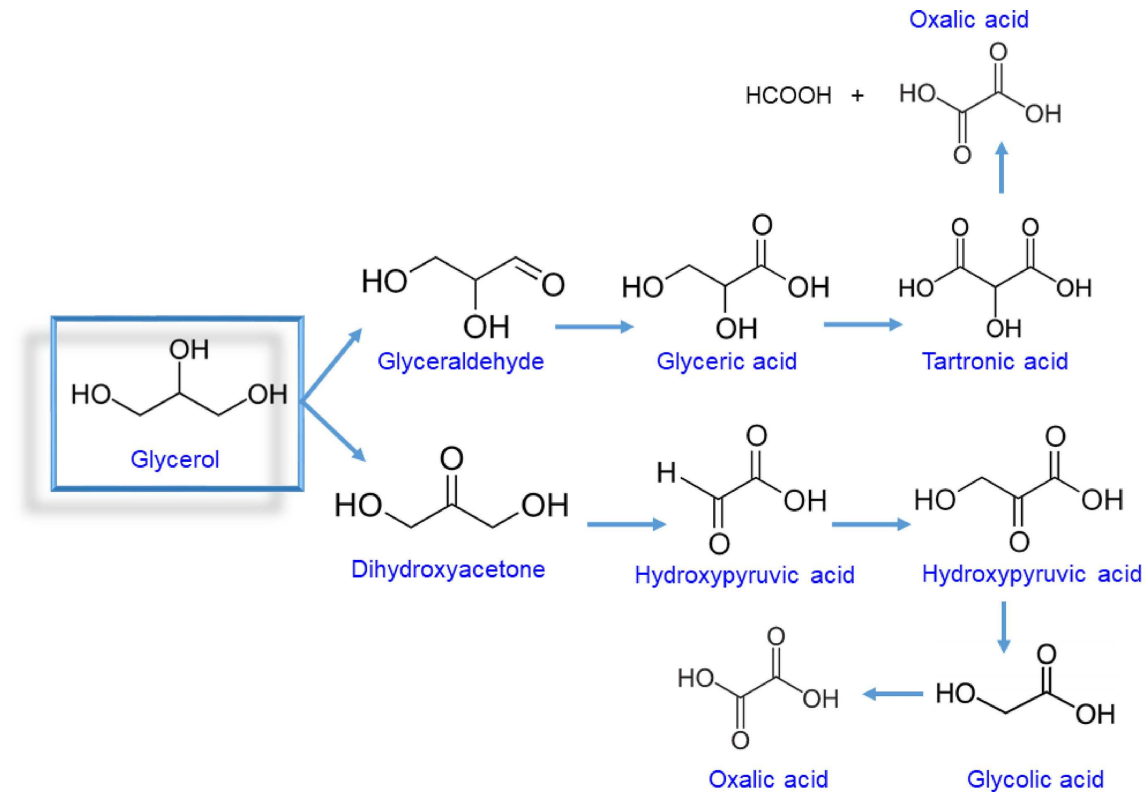

Figure 1. Pathways for glycerol selective oxidation.

temperature influenced the catalytic activity in correlation with different nanoparticles composition. ${ }^{[21]}$

Recently we reported the different behaviour in glycerol oxidation of $\mathrm{Au}-\mathrm{Ag}$ catalysts supported on alumina, synthesized by SOL immobilization and SMAD (Solvated Metal Atom Dispersion) method. ${ }^{[22]}$ Even both preparations showed synergistic effect between the two metals, a different metal distribution was revealed depending on preparation method and post treatments, which rebounded on different catalytic activity.

Based on these facts and considering the already proven efficiency of $\mathrm{Au}-\mathrm{Ag}$ bimetallic catalysts in glycerol oxidation, here we compared the catalytic activity and selectivity of differently synthesized and post-treated $\mathrm{Au} / \mathrm{Ag}-\mathrm{TiO}_{2}$ catalysts. Synthesis by deposition precipitation with urea (DPU) was compared with sol-immobilization synthesis. The effect of calcination and reduction treatments has been investigated as a function of the catalyst preparation method and $\mathrm{Au} / \mathrm{Ag}$ atomic ratio $(1: 1$ and $4: 1)$.

\section{Experimental Section}

\section{General}

$\mathrm{HAuCl}_{4} \cdot 3 \mathrm{H}_{2} \mathrm{O}, \mathrm{AgNO}_{3}$ (purity >99.0\%), polyvinyl alcohol (PVA) $(\mathrm{MW}=9000-10,000, \quad 80 \%$ hydrolysed), poly(diallyldimethylammonium)chloride (PDDA, medium molecular weight) aqueous solution, 20 wt.\% and $\mathrm{NaBH}_{4}$ (purity $\geq 98 \%$ ) were from SigmaAldrich. $\mathrm{TiO}_{2}$ (P25 by Degussa) was the support. Glycerol (86$89 \mathrm{wt} . \%$ solution), glyceric acid and all the intermediates were from Sigma-Aldrich. Deionized water (Milli-Q purified) was used in all the experiments. Gaseous oxygen from SIAD was $99.99 \%$ pure.

\section{Synthesis by Sol Immobilization}

In sol-immobilization (SOL) synthesis, bimetallic AuAg sol were prepared by reduction of the precursors by $\mathrm{NaBH}_{4}$ in aqueous solution in presence of polyvinyl alcohol (PVA) as stabilizing agent and the support was added after nanoparticles formation. ${ }^{[23,24]}$ Bimetallic AuAg sols were prepared by consecutive reduction of the $\mathrm{AgNO}_{3}$ and $\mathrm{HAuCl}_{4}$, with $\mathrm{Au} / \mathrm{Ag}$ molar ratio equal to $1: 1$ and $4: 1$, respectively. Firstly, we mixed $\mathrm{AgNO}_{3}$ and PVA solution (0.2 wt.\%) in MilliQ water, adding after a freshly prepared $25 \mathrm{mM} \mathrm{NaBH}_{4}$ solution. The appearance of a yellow colour confirmed the reduction of $\mathrm{Ag}$. The solution was stirred for 30 minutes, then $\mathrm{HAuCl}_{4}$ mixed with PVA solution (0.2 wt.\%) added and just at once further $25 \mathrm{mM}$ $\mathrm{NaBH}_{4}$ under vigorous stirring. Solution changed colour to brown.

The appropriate amount of sol and $\mathrm{TiO}_{2}$ providing $1.0 \mathrm{wt} \%$ metal loading of final $\mathrm{AuAg} / \mathrm{TiO}_{2}$ was mixed and the adsorption of nanoparticles was favoured by addition of proper amount of PDDA solution $(0.08 \mathrm{wt} \%)$. The suspension was stirred at room temperature for $2 \mathrm{~h}$, in order to have the complete adsorption of the metal nanoparticles on the support surface, which was indicated by the complete decolouration of the liquid phase. The powder was then filtered, washed with water, and dried at $80^{\circ} \mathrm{C}$ overnight.

\section{Synthesis by Deposition-Precipitation}

Ag was first deposited by deposition-precipitation with $\mathrm{NaOH}$ (DPNaOH) followed by the deposition of Au by DPU. For that $\mathrm{TiO}_{2}$ was added to an aqueous solution of $\mathrm{AgNO}_{3}$ heated at $80^{\circ} \mathrm{C}$. The $\mathrm{pH}$ was adjusted to 9 by dropwise addition of $\mathrm{NaOH}(0.5 \mathrm{M})$, in order to promote the precipitation of $\mathrm{AgOH}$ on the support. The suspension was kept under stirring for $2 \mathrm{~h}$ at $80^{\circ} \mathrm{C}$. Gold was deposited by $\mathrm{DPU}^{[24,25]}$ method after drying the $\mathrm{Ag} / \mathrm{TiO}_{2}$ under vacuum at $80^{\circ} \mathrm{C}$ for $2 \mathrm{~h}$. The final metal loading $(\mathrm{Ag}+\mathrm{Au})$ is $1 \mathrm{wt} . \%$ for all the samples. 


\section{Post-Treatments}

Calcination was carried out at $300^{\circ} \mathrm{C}$ for $1 \mathrm{~h}$ in a tubular furnace and static air. Heating rate was $5^{\circ} \mathrm{Cmin}^{-1}$, and at the end of the treatment sample cooled down to RT. Reduction occurred at $300^{\circ} \mathrm{C}$ or $550^{\circ} \mathrm{C}$ for $1 \mathrm{~h}$ in a tubular furnace, under $\mathrm{H}_{2}$ flow. Temperature was reached through a heating rate of $5^{\circ} \mathrm{Cmin}^{-1}$ under $\mathrm{N}_{2}$ flow, as well as free cooling until RT occurred under $\mathrm{N}_{2}$ flow. The DPU reduced samples were first activated in a flow of hydrogen with a heating rate of $2{ }^{\circ} \mathrm{C} / \mathrm{min}$ up to $550^{\circ} \mathrm{C}$ followed by a plateau at the same temperature of $2 \mathrm{~h}$.

The complete samples list is reported below (Table 1).

\begin{tabular}{|c|c|c|c|}
\hline Sample name & Synthesis Method & $\mathrm{Au} / \mathrm{Ag}$ & Post-Treatment \\
\hline $\mathrm{Au}_{1} \mathrm{Ag}_{1} / \mathrm{TiO}_{2} \mathrm{SOL}$ & Sol immobilization & $1: 1$ & As prepared \\
\hline $\mathrm{Au}_{1} \mathrm{Ag}_{1} / \mathrm{TiO}_{2}$ SOL_calc & Sol immobilization & $1: 1$ & $300^{\circ} \mathrm{C}$ in air \\
\hline $\mathrm{Au}_{1} \mathrm{Ag}_{1} / \mathrm{TiO}_{2} \mathrm{DPU}$ & DPU & $1: 1$ & As prepared \\
\hline $\mathrm{Au}_{1} \mathrm{Ag}_{1} / \mathrm{TiO}_{2} \mathrm{DPU}$ red & DPU & $1: 1$ & $550^{\circ} \mathrm{C}$ in $\mathrm{H}_{2}$ \\
\hline $\mathrm{Au}_{4} \mathrm{Ag}_{1} / \mathrm{TiO}_{2} \mathrm{SOL}$ & Sol immobilization & $4: 1$ & As prepared \\
\hline $\mathrm{Au}_{4} \mathrm{Ag}_{1} / \mathrm{TiO}_{2}$ SOL_calc & Sol immobilization & $4: 1$ & $300^{\circ} \mathrm{C}$ in air \\
\hline $\mathrm{Au}_{4} \mathrm{Ag}_{1} / \mathrm{TiO}_{2} \mathrm{DPU}$ & DPU & $4: 1$ & As prepared \\
\hline $\mathrm{Au}_{4} \mathrm{Ag}_{1} / \mathrm{TiO}_{2}$ DPU_calc & DPU & $4: 1$ & $300^{\circ} \mathrm{C}$ in air \\
\hline $\mathrm{Au}_{4} \mathrm{Ag}_{1} / \mathrm{TiO}_{2}$ DPU_red & DPU & $4: 1$ & $550^{\circ} \mathrm{C}$ in $\mathrm{H}_{2}$ \\
\hline
\end{tabular}

\section{Characterization Analysis}

\section{UV-Vis Spectroscopy}

UV-visible spectra of fresh and the variously pretreated supported catalysts were recorded by an Agilent Cary 60 spectrometer with a DRA accessory in diffuse reflectance to measure the localized surface plasmon resonance (LSPR) of metallic nanoparticles.

\section{X-ray Photoelectron Spectroscopy (XPS)}

The catalyst samples pretreated variously ex situ were measured by XPS using a KRATOS XSAM 800 XPS machine for the determination of surface composition and oxidation state of the metals. Al Ka characteristic X-ray line, $40 \mathrm{eV}$ pass energy and FAT mode were applied for recording the XPS lines of Au 4f, Ag 3d, O 1s, C 1s, Ti 2p regions and $\mathrm{Ag}$ MNN Auger peaks. Ti $2 \mathrm{p}_{3 / 2}$ binding energy at $458,6 \mathrm{eV}$ was used as reference for charge compensation. The Auger parameter (AP) of silver was calculated as the sum of the kinetic energy of $\mathrm{Ag} \mathrm{M}_{5} \mathrm{~N}_{45} \mathrm{~N}_{45}$ Auger lines and the binding energy of $\mathrm{Ag} 3 \mathrm{~d}_{5 / 2}$ peak.

\section{Diffuse Reflectance Infrared Fourier TTransform Spectroscopy (DRIFTS)}

The top surface of the samples was probed by $\mathrm{CO}$ adsorption at room temperature followed by DRIFTS. Spectra were collected by a Nicolet iS50 infrared spectrometer equipped with an MCT detector, a Specac DRIFT accessory and a Specac environmental chamber with a ZnSe window. 64 scans were collected with a resolution of $4 \mathrm{~cm}^{-1}$. CO adsorption was measured in the flow of $1 \% \mathrm{CO} / \mathrm{Ar}$ after 5 minutes on as prepared or variously pre-treated samples, and the state just before $\mathrm{CO}$ addition was used as background. The spectra were presented as $\log (1 / R)$, where $R$ was the reflectance, and the
CO gas spectrum was subtracted. The as prepared samples were measured after $10 \mathrm{~min}$ under Ar flow in the DRIFT cell, the ex situ prepared ones after a short $(5 \mathrm{~min})$ refreshing in situ pre-treatment at the same temperature, and there were also longer subsequent pre-treatments applied in situ. The in situ pre-treatments were performed under synthetic air or $5 \% \mathrm{H}_{2} / \mathrm{Ar}$ flow with $10^{\circ} \mathrm{C} / \mathrm{min}$ heating rate and after a given isothermal period with cooling down to room temperature in air and Ar flow, respectively.

\section{TEM and EDS Analyses}

Electron micrographs were carried out using a ZEISS LIBRA200FE microscope equipped with a $200 \mathrm{kV}$ FEG source. Energy-dispersive $X$-ray spectra (EDS-Oxford INCA Energy TEM 200) and elemental maps were collected along with HAADF-STEM (high angular annular dark field scanning transmission electron microscopy) micrographs. Before the analysis, the samples were finely smashed in an agate mortar, suspended in isopropanol and sonicated, then each suspension was dropped onto a holey carbon-coated copper grid (300 mesh) and the solvent was evaporated. Histograms of the particle size distribution were obtained by counting onto the TEM micrographs at least 300 particles; the mean particle diameter $\left(d_{m}\right)$ was calculated by using the formula $d_{m}=\Sigma d_{i} n_{i} / \Sigma n_{i}$ where $n_{i}$ was the number of particles of diameter $d_{i}$.

\section{Catalytic Oxidation of Glycerol}

Glycerol oxidation reaction occurred at $50^{\circ} \mathrm{C}$ and 3 bar of $\mathrm{O}_{2}$, in a $30 \mathrm{~mL}$ glass reactor, equipped with heater, mechanical stirrer, gas supply system and thermometer. $10 \mathrm{~mL}$ of glycerol $0.3 \mathrm{M}$ and $\mathrm{NaOH}$ $(\mathrm{NaOH} / \mathrm{Glycerol}$ ratio $=4, \mathrm{~mol} / \mathrm{mol})$ solution was transferred in the reactor, to which the catalyst was added in order to have a glycerol $/$ metal ratio of $2000, \mathrm{~mol} / \mathrm{mol}$. Reaction started when the temperature of $50^{\circ} \mathrm{C}$ was reached. Oxygen pressure was kept controlled by a mass flowmeter. Sampling occurred periodically, analysing samples by high-performance liquid chromatography (HPLC) using a column Alltech OA-10308 $(300 \mathrm{~mm} \times 7.8 \mathrm{~mm})$ with UV and refractive index (RI) detection. The eluent was a $\mathrm{H}_{3} \mathrm{PO}_{4}$ $0.1 \%$ wt. solution.

\section{Results}

\subsection{Characterization of $1 \% \mathrm{Au}_{1} \mathrm{Ag}_{1} / \mathrm{TiO}_{2}$}

$1 \% \mathrm{Au}_{1} \mathrm{Ag}_{1} / \mathrm{TiO}_{2}$ was synthesized by sol-immobilisation and sequential DPU method. ${ }^{[17,21]}$ The evolution of the bimetallic particles as a function of the different post-synthesis treatments (i.e. calcination, reduction with $\mathrm{H}_{2}$ ) has been investigated.

As evidenced by HAADF-STEM/EDS analysis, the SOL preparation provided bimetallic particles already in the as prepared (fresh) catalyst (Figure 2). The average composition of the particles resulted very close to the nominal value (Au atomic $\%=48.5 \pm 5$ ). However, as visible on Figure 3 , the LSPR band of the as prepared bimetallic $\mathrm{Au}_{1} \mathrm{Ag}_{1} / \mathrm{TiO}_{2} \mathrm{SOL}$ does not show the blue shift compared to that of the corresponding monometallic $\mathrm{Au} / \mathrm{TiO}_{2}$ towards that of $\mathrm{Ag} / \mathrm{TiO}_{2}(451 \mathrm{~nm})$ due to AuAg alloying as expected. ${ }^{[13,17]}$ Both appears at about $533 \mathrm{~nm}$, on the contrary, that the LSPR of parent $\mathrm{Au}_{1} \mathrm{Ag}_{1}$ sols at $489 \mathrm{~nm}$ was about $30 \mathrm{~nm}$ lower than the LSPR of the Au sol. In supported form likely due to drying and storing in air the 

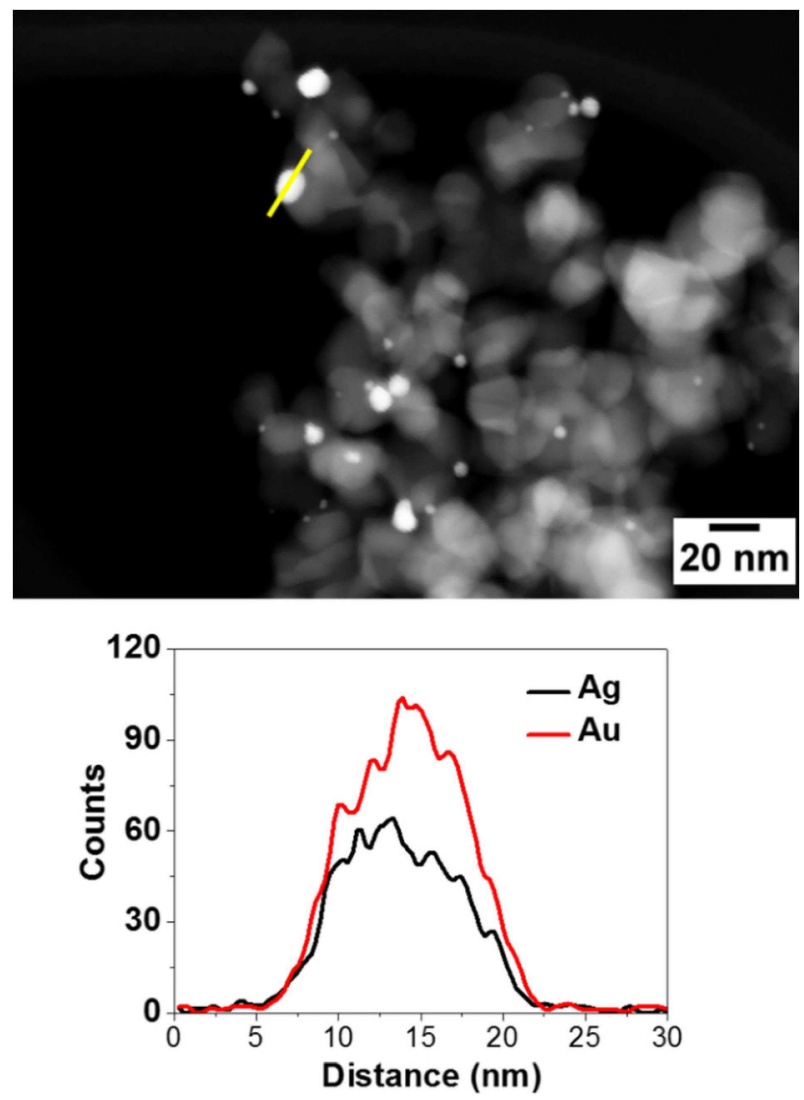

Figure 2. Representative HAADF-STEM micrograph (top) and EDS particle profile of the selected particle (bottom) of SOL-derived $\mathrm{Au}_{1} \mathrm{Ag}_{1} / \mathrm{TiO}_{2}$ (as prepared).

surface $\mathrm{Ag}$ was oxidized somewhat causing a red shift (as was observed on $\mathrm{O}_{2}$ contact at room temperature of freshly reduced $\mathrm{Ag} / \mathrm{TiO}_{2}{ }^{[21]}$ ) compensating the blue shift resulting from alloying. The UV-vis spectra of the as prepared Au1 Ag1/TiO2_DPU and the corresponding monometallic samples show only very weak LSPR bands suggesting the presence of $\mathrm{Au}$ and Ag dominantly in oxidised form. In DPU samples gold and silver reduced extensively above $80^{\circ} \mathrm{C}$, and the formation of bimetallic nanoparticles was reported to start over $155^{\circ} \mathrm{C} .{ }^{[17]}$ At temperatures higher than $155^{\circ} \mathrm{C}$, the plasmon shifts to lower wavelength $\left(515 \mathrm{~nm}\right.$ at $\left.300-350^{\circ} \mathrm{C}\right)$ between that of silver $(475 \mathrm{~nm})$ and that of gold $(530 \mathrm{~nm})$, confirming the formation of bimetallic particles. ${ }^{[17]}$

In calcined state the enhanced intensity LSPR band of $\mathrm{Au}_{1} \mathrm{Ag}_{1} / \mathrm{TiO}_{2} \mathrm{SOL}$ and $\mathrm{Au} / \mathrm{TiO}{ }_{2} \mathrm{SOL}$ was red shifted compared to the as prepared state, in lower extent in the case of $\mathrm{Au} / \mathrm{TiO}_{2}$. The larger intensity indicates particle size increase, ${ }^{[26]}$ that is in agreement with the particle size determined by TEM (Figure 4). The original $2.7 \mathrm{~nm}$ mean diameter changed to 5.3 during calcination (see in Table 2). The red shift might be due to the removal of organic residues from the $\mathrm{Au}(\mathrm{Ag}) \mathrm{NPs}$ accompanied with an enhanced interaction with the support, plus in case of the bimetallic sample likely due to an extended oxidation of surface silver. The SOL derived $\mathrm{Ag} / \mathrm{TiO}_{2}$ decolourized in calcination, its LSPR disappeared, silver must be oxidized. In the
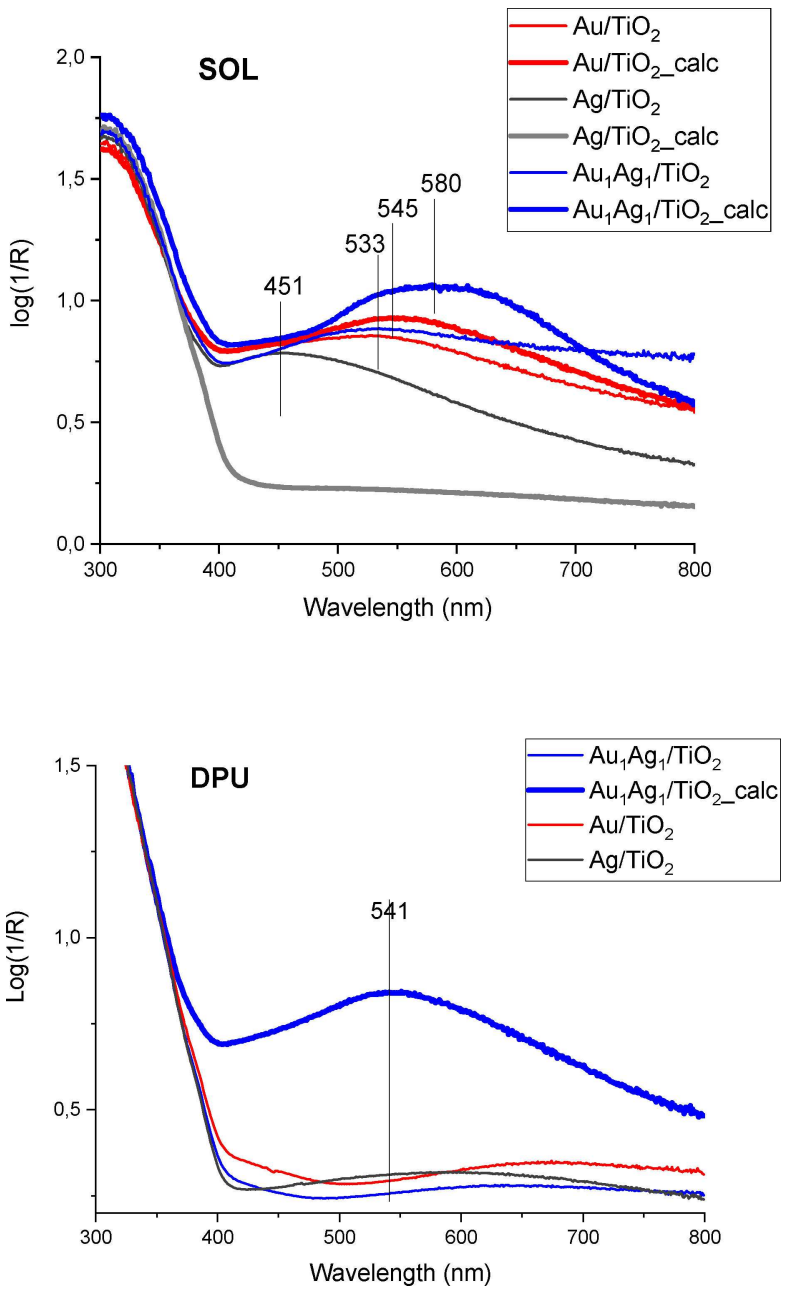

Figure 3. UV-vis of $\mathrm{Au}_{1} \mathrm{Ag}_{1} / \mathrm{TiO}_{2} \mathrm{SOL}$ (top image) and $\mathrm{Au}_{1} \mathrm{Ag}_{1} / \mathrm{TiO}_{2} \mathrm{DPU}$ (bottom image) before and after calcination. Monometallic $\mathrm{Au}$ and $\mathrm{Ag}$ are reported as reference.

calcination of DPU derived $\mathrm{Au}_{1} \mathrm{Ag}_{1} / \mathrm{TiO}_{2}$ plasmonic NPs evolved indicated by LSPR band $(541 \mathrm{~nm})$ at somewhat lower wavelength than measured for calcined $\mathrm{Au} / \mathrm{TiO}_{2} \mathrm{SOL}(545 \mathrm{~nm})$ as a result of reduction of $\mathrm{Au}$ and $\mathrm{Ag}$ and also alloy formation.

Studying by XPS (Table 2) the surface composition, monometallic SOL samples showed that even after calcination $\mathrm{Au}$ is not fully reduced and a fraction of $\mathrm{Au}^{\delta+}$ is still present $\left(\mathrm{Au}^{+} / \mathrm{Au}^{0}=0.21\right)$. This could be partially ascribed to the interaction with $\mathrm{TiO}_{2}$. The fresh bimetallic SOL showed a Ag enrichment at the surface ( $\mathrm{Au} / \mathrm{Ag}$ atomic ratio 0.63 ). In this case $\mathrm{Au}$ is rather in $\mathrm{Au}^{\delta+}$ state and $\mathrm{Ag}$ presented an Auger parameter (719.5) consistent with the metallic state as well according to Ferraria et al., ${ }^{[27]}$ that reported $\mathrm{AP}=720.5,717.8$ and 718.4 for metallic silver, $\mathrm{Ag}_{2} \mathrm{O}$ and $\mathrm{AgO}$. After calcination, we observed particle growth (from $2.7 \mathrm{~nm}$ to $5.3 \mathrm{~nm}$ ) (Figures 4) and Ag appeared not totally oxidized as the $\operatorname{AP}(718,4)$ assumes an intermediate value between the one of metallic and the oxidized one. However, in calcined SOL $\mathrm{Ag} / \mathrm{TiO}_{2}(\mathrm{AP}=717.7)$ silver is oxidized. Also, $\mathrm{Au}$, as in the monometallic sample, is partially present as $\mathrm{Au}^{\delta+}$ in almost the same ratio (0.26) as in 

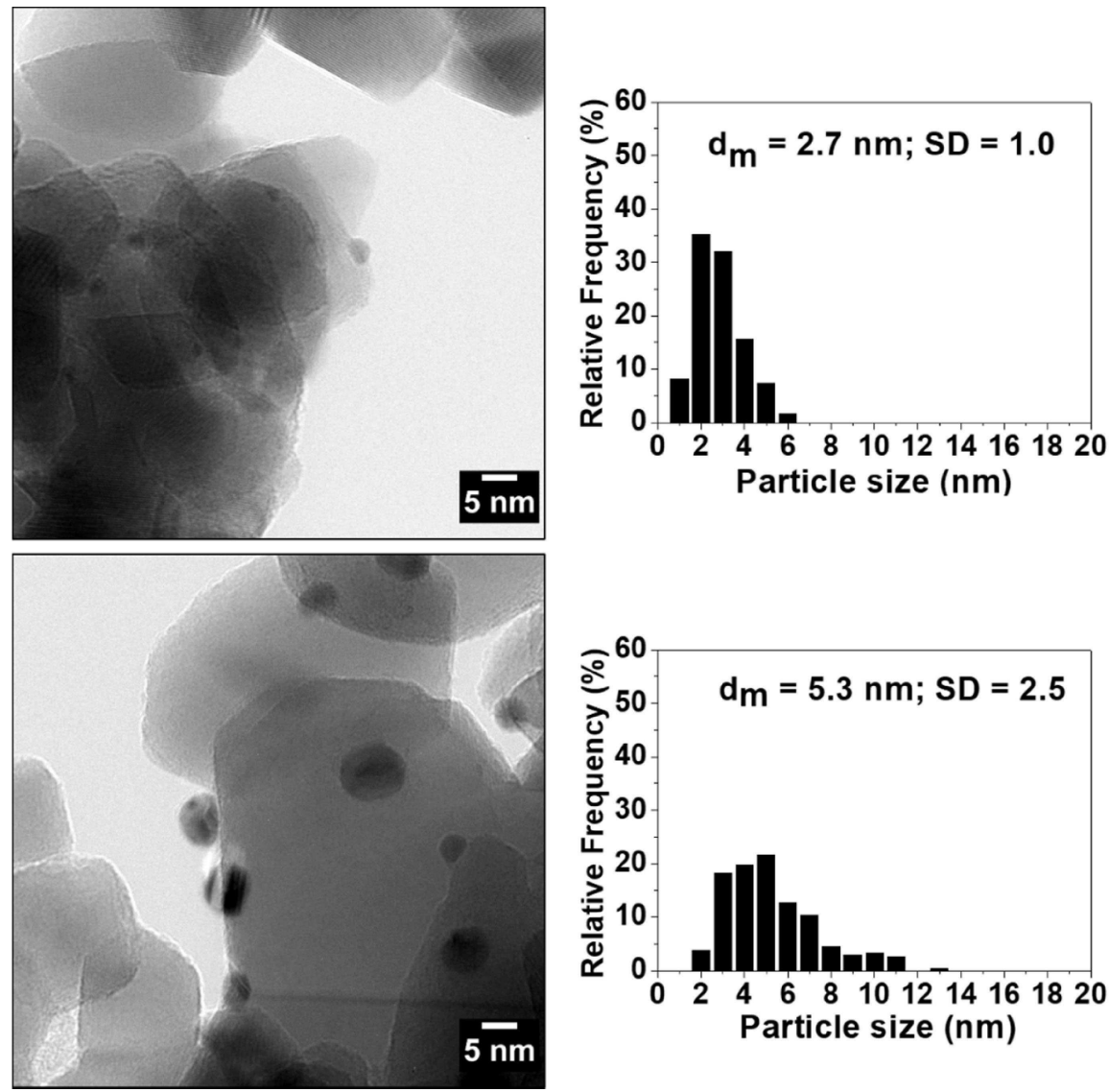

Figure 4. Representative HRTEM micrograph and histogram of particle size distribution of SOL-derived $\mathrm{Au}_{1} \mathrm{Ag}_{1} @ \mathrm{TiO}_{2}$ fresh (top) and calcined (bottom).

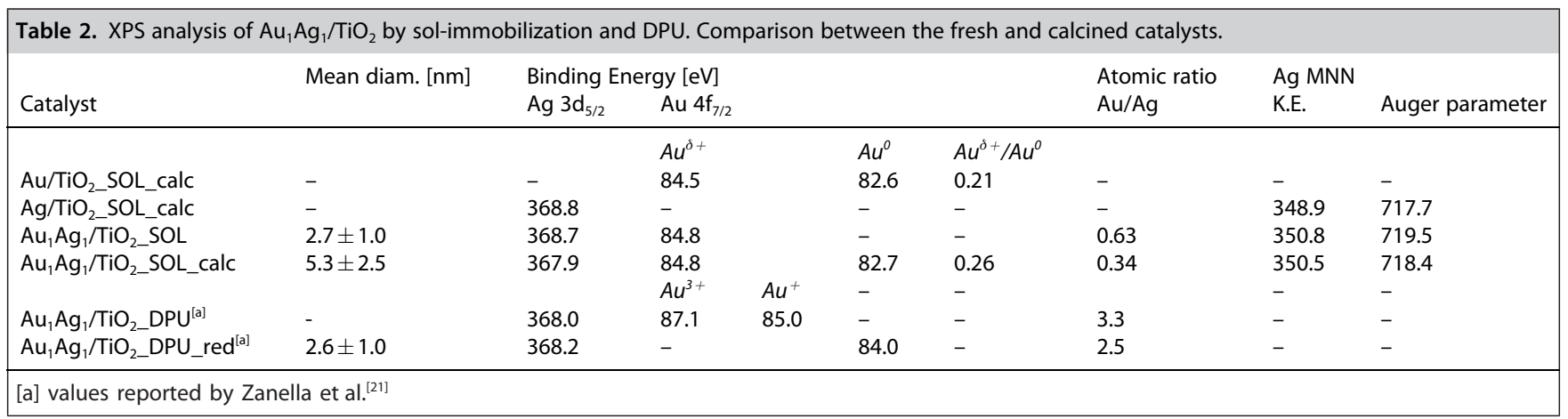

the previous case. This finding indicates a reciprocal interaction between $\mathrm{Ag}$ and $\mathrm{Au}$ possibly mediated by $\mathrm{TiO} 2$ able to install strong metal-support interaction (SMSI). Moreover, the thermal treatment, as expected, increased the enrichment of $\mathrm{Ag}$ at the surface (Au/Ag at.\% 0.34).

DPU-derived catalysts, already reported by Zanella et al., ${ }^{[21]}$ in the fresh state showed two peaks for $\mathrm{Au}\left(4 \mathrm{f}_{7 / 2}\right)$ at 87.1 and $85.0 \mathrm{eV}$ (Table 2). The peak at B.E. $87.1 \mathrm{eV}$ refers to $\mathrm{Au}^{\prime \prime \prime}$, due to the formation of a Au'l'-urea complex on $\mathrm{TiO}_{2}$; the one at 85.0 was attributed to $A u^{\prime}$, addressed to the reduction of part of the $\mathrm{Au}^{\text {III }}$ species under XPS beam. The binding energy value of $\mathrm{Ag}$ $\left(3 d_{5 / 2}\right)$ at $368.0 \mathrm{eV}$ is between those of $\mathrm{Ag}^{\circ}$ and $\mathrm{Ag}^{+}$, ascribed by the Authors to partial reduction due to the XPS experiments.
After in situ reduction, $\mathrm{Au}$ is in the metallic form, and we expected that also $\mathrm{Ag}$ is completely reduced. The DPU samples presented $\mathrm{Au} / \mathrm{Ag}$ ratios particularly high with respect to the nominal ones (3.3 in the fresh and 2.5 in the reduced) highlighting Au enrichment at the surface which decreased due to the thermal (reducing) treatment. The particularly high value compared to the nominal one was also addressed to Ag partial segregation as $\mathrm{AgCl}^{[17]}$ on titania surface and $\mathrm{Au}$ as $\mathrm{Au}^{\text {III-}}$-urea complex ${ }^{[24]}$ with no interaction between each other. To note that DPU sample after the thermal treatment is characterized by smaller particle size than the SOL ones ( $2.6 \mathrm{~nm}$ vs $5.3 \mathrm{~nm}$ ).

Distribution and oxidation state of the metals were also studied by CO-DRIFT experiments (Figure $5 a-b$ ). To note that 

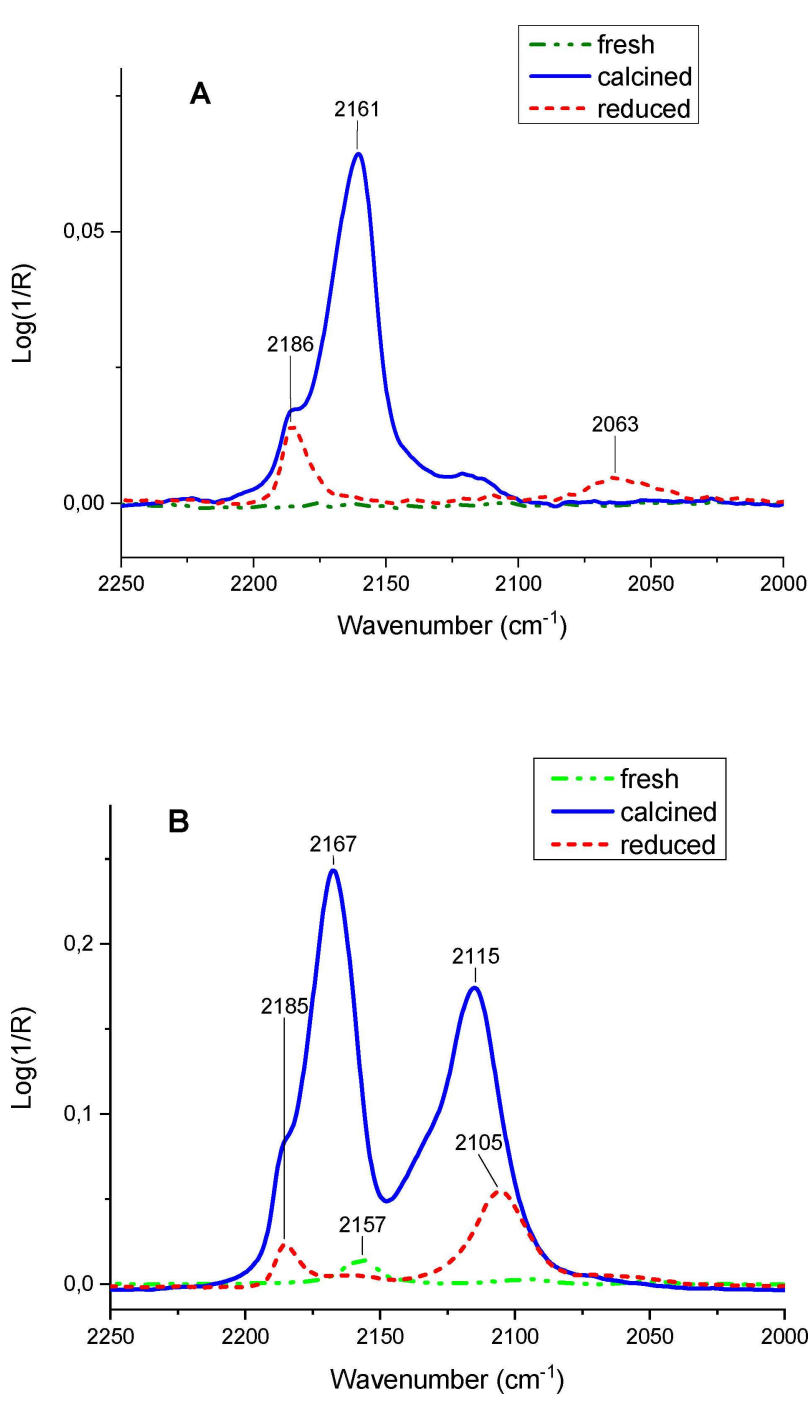

Figure 5. DRIFT measurement of $\mathrm{CO}$ adsorption at room temperature on $\mathrm{Au}_{1} \mathrm{Ag}_{1}$ supported on $\mathrm{TiO}_{2}$ by SOL (top image) and DPU (bottom image). Comparison between fresh (green line), reduced (red line) and calcined (blue line) samples.

$\mathrm{CO}$ is very weakly adsorbed on $\mathrm{Ag}^{0}$ species. The band at $2105 \mathrm{~cm}^{-1}$ refers to $\mathrm{Au}^{0}-\mathrm{CO}$ species. ${ }^{[28]}$ The frequency of $2055 \mathrm{~cm}^{-1}$ corresponds to $\mathrm{CO}$ adsorbed on $\mathrm{Ag}^{0}$, while the band at $2160 \mathrm{~cm}^{-1}$ refers to $\mathrm{Ag}^{+}$. Comparing $\mathrm{SOL}$ and DPU-prepared samples, $\mathrm{CO}$ signals in SOL catalysts appeared generally weaker than in the DPU ones. This behaviour can be connected to the presence of PVA molecules adsorbed on the SOL-samples surface thus limiting the adsorption of $\mathrm{CO}$.

The $\mathrm{CO}$ adsorption bands helped in the interpretation of XPS results. In the SOL (Figure 5a) we did not observe any signals in the fresh sample due to the presence of PVA and eventually PDDA residues and water thus limiting the CO adsorption (green line). This result is also consistent with XPS that indicates a surface where $\mathrm{AgO}$ is covering the $\mathrm{Au}^{0}$. After calcination Ag is oxidized even partially (XPS) and a strong peak at $2161 \mathrm{~cm}^{-1}$ due to $\mathrm{CO}$ adsorbed on $\mathrm{Ag}^{+}$appeared (blue line). $\mathrm{Au}^{0}$ is almost submerged by $\mathrm{Ag}$ in agreement with XPS $\mathrm{Au} / \mathrm{Ag}$ ratio that decreases after calcination with respect to the original fresh sample value. DPU (Figure $5 b$ ) reduced sample (red line) presented only the peak at $2105 \mathrm{~cm}^{-1}$ due to the presence of metallic $\mathrm{Au}$ whereas after calcination (blue line) both peaks (2115 and $2167 \mathrm{~cm}^{-1}$ ) related to $\mathrm{Au}^{0}$ and $\mathrm{Ag}^{+}$. A shoulder at $2132 \mathrm{~cm}^{-1}$ ascribed to $\mathrm{Au}^{\delta+}$ appears. The results are in agreement with XPS data if we consider the double contribution of Gold $(0$ and $\delta+)$ compared to the Ag signal. Here the amount of gold at the surface is higher than the silver.

\subsection{Characterization of $1 \% \mathrm{Au}_{4} \mathrm{Ag}_{1}$}

As well as the $\mathrm{Au} / \mathrm{Ag}$ 1:1 samples, $\mathrm{Au}_{4} \mathrm{Ag}_{1} / \mathrm{TiO}_{2}$ were fully characterized as prepared, after calcination and after reduction with $\mathrm{H}_{2}$.

UV-VIS analysis of SOL samples (Figure 6) showed also in the case of $4: 1$ as in case of $1: 1$ composition discussed earlier

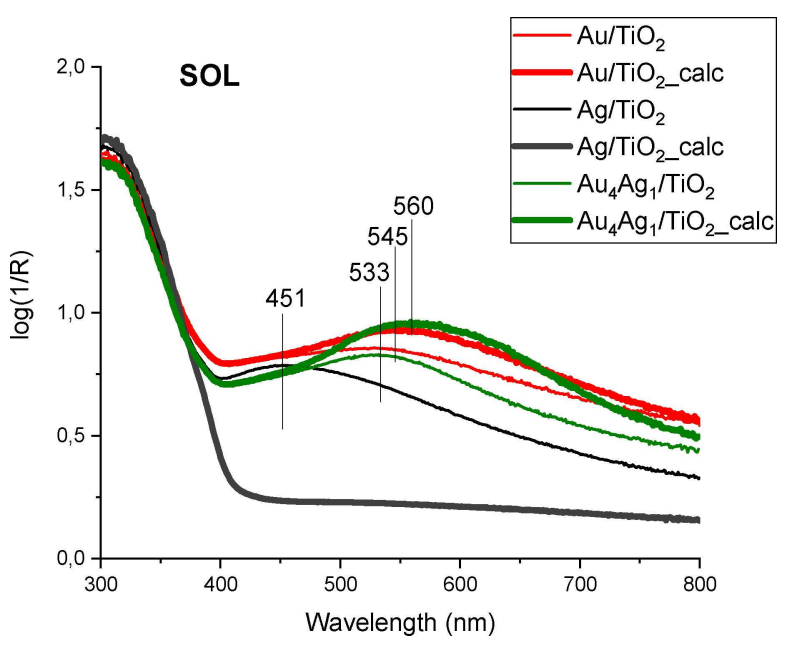

Figure 6. UV-vis of $\mathrm{Au}_{4} \mathrm{Ag}_{1} / \mathrm{TiO}_{2} \mathrm{SOL}$ before and after calcination.

the plasmon peak at about the same wavelength $(533 \mathrm{~nm})$ in as prepared state and red shifted $(560 \mathrm{~nm})$ compared to monometallic $\mathrm{Au} / \mathrm{TiO}_{2}(545 \mathrm{~nm})$ in calcined state, instead of blue shift due to alloying. Similar explanation applies here as earlier. The Ag segregated and partially oxidized on the surface of the bimetallic particles, but in lower extent than on 1:1 case results in larger red shift than the alloying in opposite direction.

For DPU samples UV-Vis spectra (Figure 7) did not show any peak for fresh samples (no metallic nanoparticles) as expected, whereas a plasmon band appeared after reduction or calcination also at $560 \mathrm{~nm}$ like in case of the corresponding SOL sample.

$1 \% \mathrm{Au}_{4} \mathrm{Ag}_{1} / \mathrm{TiO}_{2}$ fresh sample prepared by SOL showed mean particle size larger than the fresh sample prepared by DPU (mean diameter $=2.9 \mathrm{~nm}$ and $1.1 \mathrm{~nm}$, respectively) (Figures 8 and 10). Moreover, particle size resulted differently affected by calcination treatment. After calcination, SOL sample showed a broader particle size distribution with a mean 


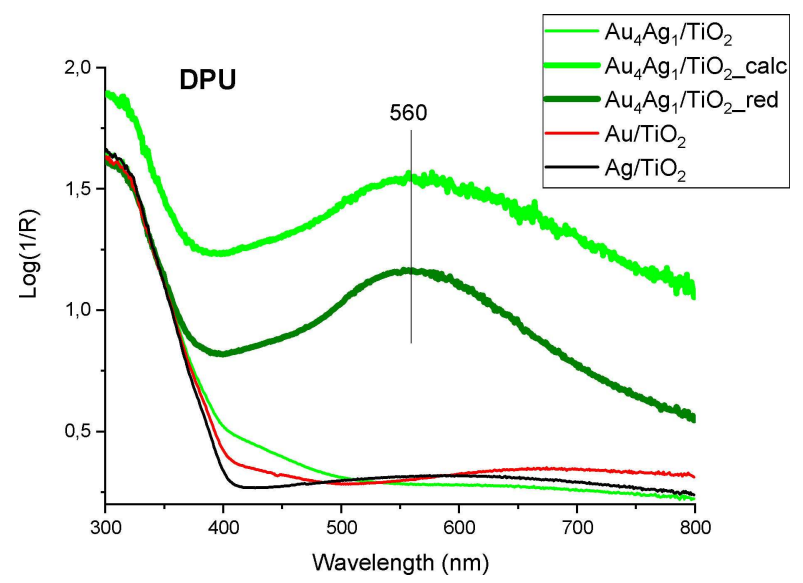

Figure 7. UV-vis of DPU-derived catalysts after different treatments.

diameter of $5.1 \mathrm{~nm}$ (Figure 8 bottom), whereas in the case of DPU sample, the particle size increased till $2.4 \mathrm{~nm}$, with a particle size distribution considerably narrower than the sol case (Figure 10 bottom). AuAg particles in SOL-derived catalysts showed an average $\mathrm{Au} / \mathrm{Ag}$ molar ratio of 4.6 calculated on EDS analysis on single particle, which is similar to the nominal one. In the case of DPU-derived catalysts, EDS analysis revealed an average $\mathrm{Au} / \mathrm{Ag}$ molar ratio of 7.3 (Figure 11), higher than the nominal one, which can be explained, as in the case of $1: 1$ $\mathrm{Au}: \mathrm{Ag}$ sample, with a partial segregation of $\mathrm{Ag}$ as $\mathrm{AgCl}$. Indeed,

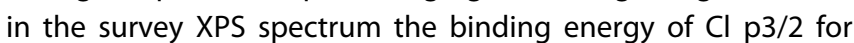
metal chloride appears at $\sim 198.5-199 \mathrm{eV}$ that could be associated to the presence of chlorides of $\mathrm{AgCl}$. Bimetallic particles were gold-rich at the surface.

XPS analyses (Table 3) showed in the fresh $\mathrm{Au}_{4} \mathrm{Ag}_{1} / \mathrm{TiO}_{2}$ prepared by DPU the presence of gold in the $\mathrm{Au}^{\prime \prime \prime}$ and $\mathrm{Au}^{\prime}$ form (B.E $87.3 \mathrm{eV}$ and $84.8 \mathrm{eV}$ ) as in the case of the $1: 1 .^{[24]}$ The $\mathrm{Au}^{3+} / \mathrm{Au}^{+}$ratio evidenced the higher contribution of $\mathrm{Au}^{+}$than of $\mathrm{Au}^{3+}$.The AP of $\mathrm{Ag}(721)$ is particularly high indicating the presence of at least partially reduced oxidation state. The ratio between $\mathrm{Au}$ and $\mathrm{Ag}$ (9.1) indicates a very high exposure of $\mathrm{Au}$. Reduction in $\mathrm{H}_{2}$ at high temperature $\left(550^{\circ} \mathrm{C}\right)$ decreases the $\mathrm{Au} /$ Ag ratio to 4.2 (similar to the nominal value), confirming the migration of $\mathrm{Ag}$ atoms toward the surface of nanoparticle. $\mathrm{Au}$ is not fully reduced and $\mathrm{Au}^{\delta+} / \mathrm{Au}^{0}$ is 0.23 . Ag presents an AP decreased with respect to the one of the fresh counterpart that could indicates a partial oxidation of $\mathrm{Ag}$ as for $\mathrm{Au}$. Interestingly, calcination in air forms the same distribution of species except for the $\mathrm{Ag} / \mathrm{Au}$ ratio that resulted higher than the one obtained by reduction (6.4 vs 4.2). The two catalysts thus differ from the $\mathrm{Au}$ exposure at the surface but apparently in both cases Ag and $\mathrm{Au}$ are present with the same oxidation states. Our opinion is that $\mathrm{TiO}_{2}$ is able to interact with the metals through the thermal treatment provoking strong support-metal interaction thus
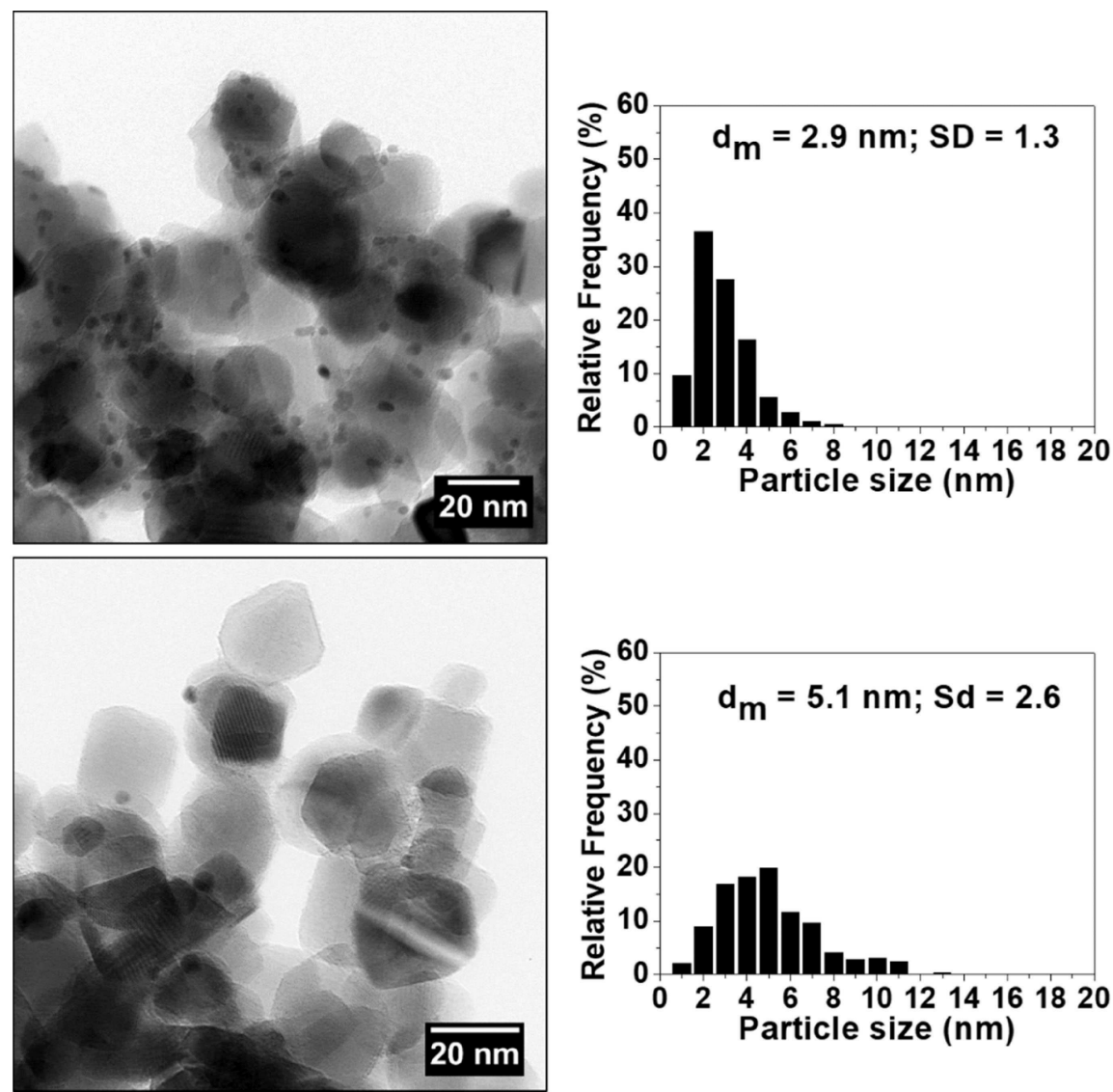

Figure 8. Representative HRTEM micrograph and histogram of particle size distribution of SOL-derived $\mathrm{Au}_{4} \mathrm{Ag}_{1} / \mathrm{TiO}_{2}$ fresh (top) and calcined (bottom). 


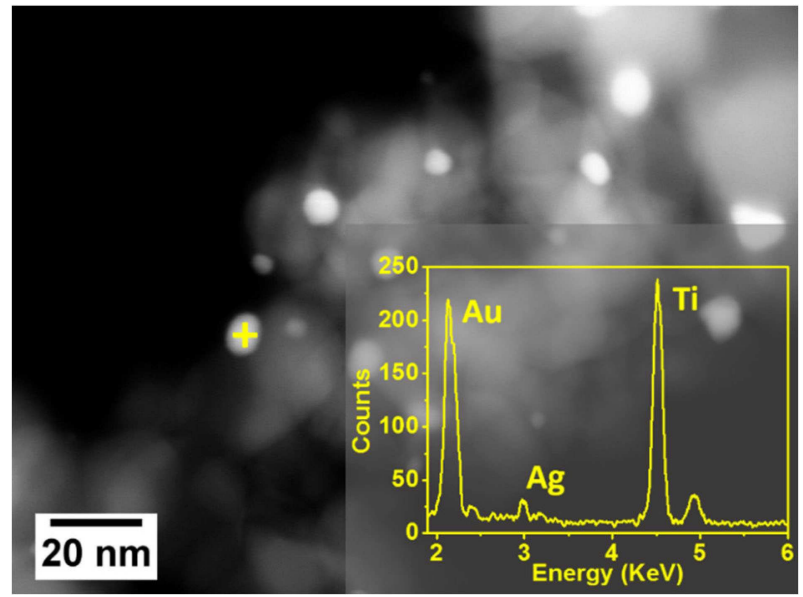

Figure 9. HAADF-STEM micrograph and EDS spectrum (inset) carried out on a single particle $\mathrm{SOL}$-derived $\mathrm{Au}_{4} \mathrm{Ag}_{1} / \mathrm{TiO}_{2}$ calcined.

providing the same distribution of oxidation numbers regardless the atmosphere. In the case of $\mathrm{Au}_{4} \mathrm{Ag}_{1} / \mathrm{TiO}_{2}$ prepared by SOL immobilization, again a $\mathrm{Au}^{\delta+} / \mathrm{Au}^{0}$ ratio around 0.27 is obtained thus confirming the important role of the support in determining the presence of $\mathrm{Au}^{\delta+}$. The $\mathrm{Au} / \mathrm{Ag}$ atomic ratio was 3.6 similar to the nominal value in the fresh sample, but it

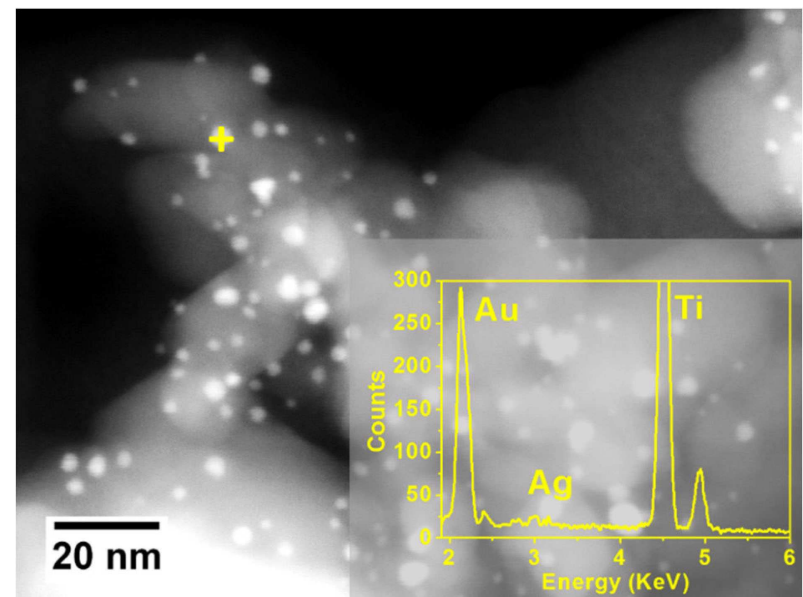

Figure 11. HAADF-STEM micrograph and EDS spectrum (inset) carried out on a single particle DPU-derived $\mathrm{Au}_{4} \mathrm{Ag}_{1} / \mathrm{TiO}_{2}$ calcined.

increased to 4.7 after calcination. These values are very similar to the one obtained by EDS-TEM analysis, confirming the alloyed nature of the bimetallic particles (Figure 9). As in the case of DPU, the APs of silver indicate in both cases (fresh and calcined) a similar oxidation state which is not sensitive to the treatment.
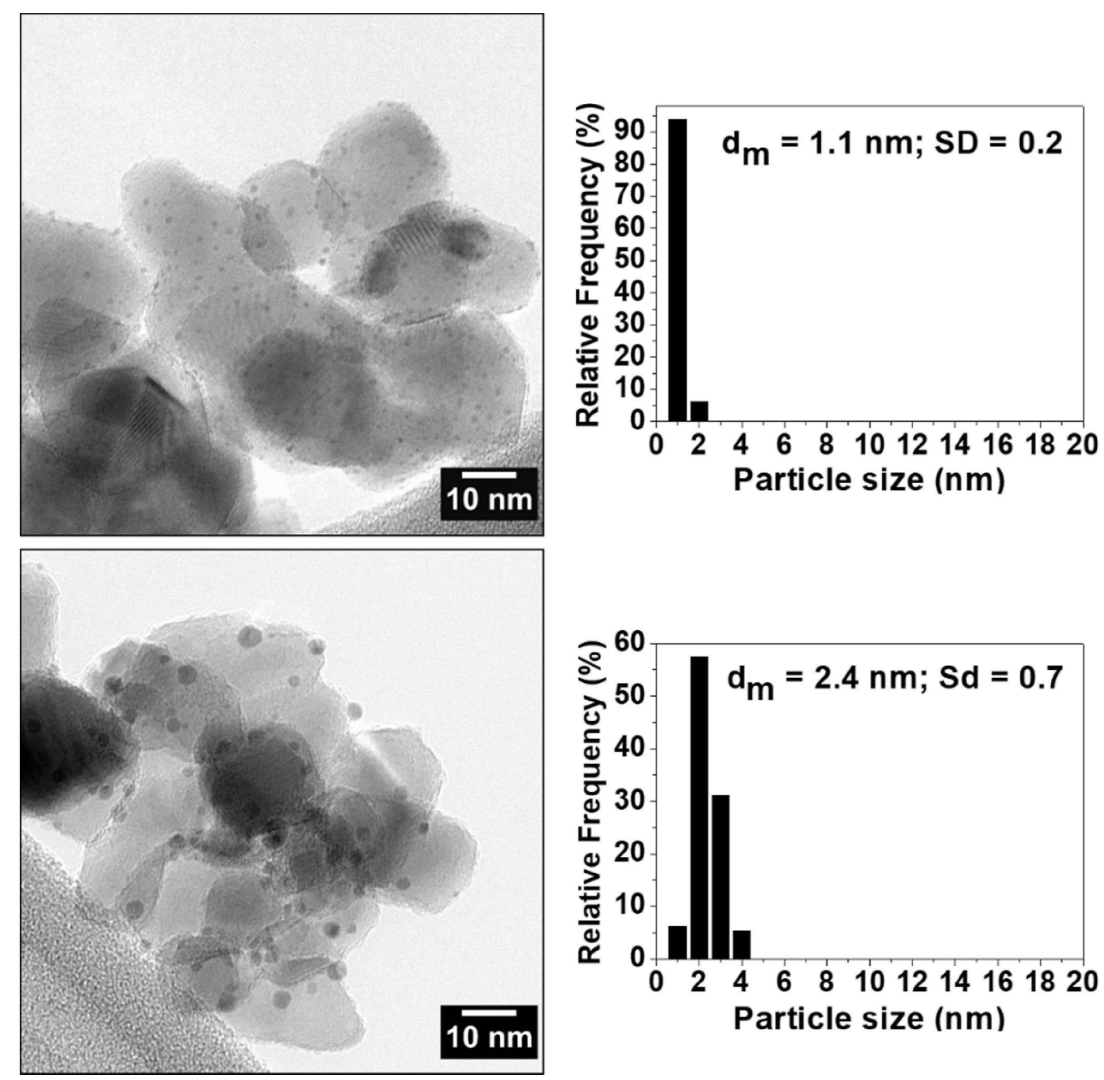

Figure 10. Representative HRTEM micrograph and histogram of particle size distribution of DPU-derived $\mathrm{Au}_{4} \mathrm{Ag}_{1} / \mathrm{TiO}_{2}$ fresh (top) and calcined (bottom). (Calcination at $300^{\circ} \mathrm{C}$ in air or in $\mathrm{H}_{2}$ gave the same result). 


\begin{tabular}{|c|c|c|c|c|c|c|c|c|c|}
\hline \multirow[b]{2}{*}{ Catalyst } & \multirow[t]{2}{*}{ Mean diam. [nm] } & \multicolumn{5}{|c|}{ Binding Energy [eV] } & \multirow{2}{*}{$\begin{array}{l}\text { Atomic ratio } \\
\mathrm{Au} / \mathrm{Ag}\end{array}$} & \multicolumn{2}{|l|}{ Ag MNN } \\
\hline & & $\operatorname{Ag} 3 d_{5 / 2}$ & $\mathrm{Au} 4 \mathrm{f}_{7}$ & & & Ti $2 p_{3 / 2}$ & & & Auger Parameter \\
\hline & \multirow[b]{2}{*}{$1.1 \pm 0.2$} & & $A u^{3+}$ & $\mathrm{Au}^{+}$ & $A u^{3+} / A u^{+}$ & \multirow[b]{2}{*}{458.6} & \multirow[b]{2}{*}{9.1} & \multirow[b]{2}{*}{352.9} & \multirow[b]{2}{*}{721.0} \\
\hline $\mathrm{Au}_{4} \mathrm{Ag}_{1} / \mathrm{TiO}_{2} \mathrm{DPU}$ & & 368.1 & 87.2 & 84.8 & 0.46 & & & & \\
\hline $\mathrm{Au}_{4} \mathrm{Ag}_{1} / \mathrm{TiO}_{2} \mathrm{DPU}$ red & $2.4 \pm 0.7$ & 366.9 & 85.4 & 83.0 & 0.23 & 458.6 & 4.2 & 352.9 & 719.8 \\
\hline $\mathrm{Au}_{4} \mathrm{Ag}_{1} / \mathrm{TiO}_{2}$ DPU_calc & $2.4 \pm 0.7$ & 367.0 & 85.4 & 83.2 & 0.29 & 458.6 & 6.4 & 352.4 & 719.4 \\
\hline $\mathrm{Au}_{4} \mathrm{Ag}_{1} / \mathrm{TiO}_{2} \mathrm{SOL}$ & $2.9 \pm 1.3$ & 367.7 & 86.2 & 83.8 & 0.26 & 458.6 & 3.6 & 353.0 & 720.7 \\
\hline $\mathrm{Au}_{4} \mathrm{Ag}_{1} / \mathrm{TiO}_{2}$ SOL_calc & $5.1 \pm 2.6$ & 367.3 & 86.0 & 83.4 & 0.28 & 458.6 & 4.7 & 352.8 & 720.1 \\
\hline
\end{tabular}

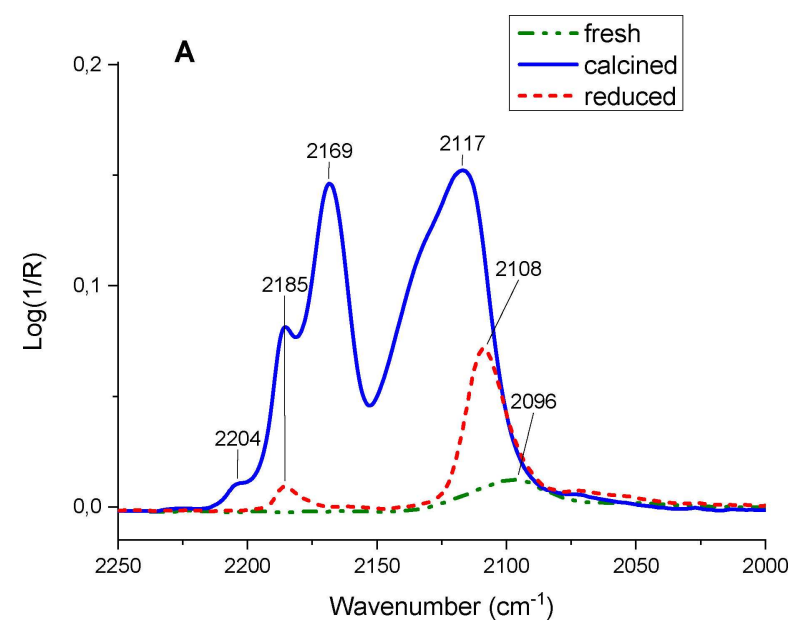

Figure 12. DRIFT measurement of $\mathrm{CO}$ adsorption at room temperature on $\mathrm{Au}_{4} \mathrm{Ag}_{1}$ supported on $\mathrm{TiO}_{2}$ by $\mathrm{SOL}$ Comparison between fresh (green line), reduced (red line) and calcined (blue line) samples.

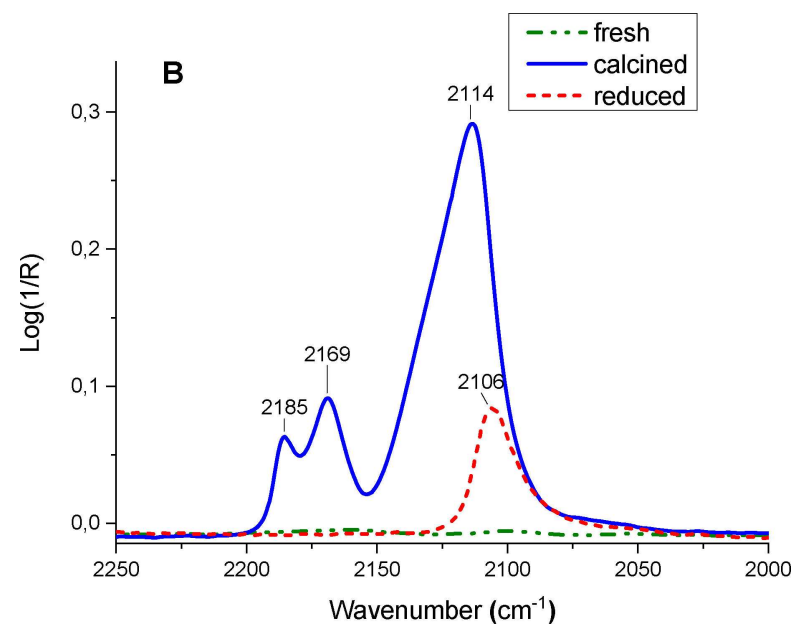

Figure 13. DRIFT measurement of $\mathrm{CO}$ adsorption at room temperature on $\mathrm{Au}_{4} \mathrm{Ag}_{1}$ supported on $\mathrm{TiO}_{2}$ by DPU. Comparison between fresh (green line), reduced (red line) and calcined (blue line) samples.

To confirm these findings, we studied the behaviour of $\mathrm{CO}$ adsorption by DRIFT analyses (Figures 12 and 13).

CO-DRIFT measurements on $\mathrm{SOL}$ catalysts (Figure 12) revealed only a weak peak at $2096 \mathrm{~cm}^{-1}$ which can indicate Au in the metallic state but shielded by the protective agent (PVA).
The peak due to adsorption of $\mathrm{CO}$ on $\mathrm{Au}^{0}$ becomes more important after calcination $\left(2117 \mathrm{~cm}^{-1}\right)$ with a shoulder at $2132 \mathrm{~cm}^{-1}$ that can be addressed to the presence of partially oxidized $\mathrm{Au} . \mathrm{Ag}^{+}$is also detected in the calcined sample with the peak at $2169 \mathrm{~cm}^{-1}$. Considering the double contribution of $\mathrm{CO}$ adsorbed on $\mathrm{Au}$ in different oxidation state, the result is consistent with the Au/Ag measured by XPS (0.26).

In the case of DPU samples, the CO-DRIFT spectra (Figure 13) indicated a situation similar to the SOL catalysts. The fresh DPU catalyst (green line) showed no peaks. After reduction (red line) the peak correlated to the presence of $\mathrm{Au}^{0}$ appeared at $2106 \mathrm{~cm}^{-1}$. No signals for $\mathrm{Ag}$ were detected. Considering that by XPS we obtained the same AP by reduction or calcination of DPU sample (meaning $\mathrm{Ag}$ in the same oxidation state), but after calcination a clear signal due to the presence of $\mathrm{Ag}^{+}$appeared, we concluded that in the reduced sample $\mathrm{Ag}^{+}$signal is lost due to the lower intensity of signals. Calcination shifted the peak of $\mathrm{Au}^{0}$ at $2114 \mathrm{~cm}^{-1}$ with the presence, as in the case of SOL, of a shoulder at $2132 \mathrm{~cm}^{-1}$. The peak of $\mathrm{Ag}^{+}$appeared at $2169 \mathrm{~cm}^{-1}$. In agreement with the XPS analyses, the relative ratio between $\mathrm{Au}$ and $\mathrm{Ag}$ in the DPU samples appeared higher than in the SOL samples.

\subsection{Catalytic Activity in Glycerol Oxidation}

All the catalysts prepared by DPU and by SOL were tested in the selective glycerol oxidation under mild conditions $\left(50^{\circ} \mathrm{C}\right.$, 3 bar of $\mathrm{O}_{2}$, glycerol $/$ metal ratio of $2000 \mathrm{~mol} / \mathrm{mol}, \mathrm{NaOH} / \mathrm{glycerol}$ of 4). $1 \% \mathrm{Au}_{1} \mathrm{Ag}_{1} / \mathrm{TiO}_{2}$ catalysts (not reported in Table 4) didn't show any activity even if Au monometallic catalysts resulted active. In the case of monometallic Au, the catalytic behaviour of SOL calcined is similar to the one of DPU reduced (1662 vs $\left.1679 \mathrm{~h}^{-1}\right)$.

However, when $\mathrm{Au} / \mathrm{Ag}$ ratio was $4: 1$, catalysts not only became active in glycerol oxidation (Table 4) but they also showed synergistic effect by the combination of the two metals. Considering that $1: 1$ samples are inactive regardless metal distribution (gold rich surface in DPU and silver rich surface in $\mathrm{SOL}$ ) and metal oxidation state (fresh, calcined, reduced), we concluded that the synergistic effect (and therefore the activity) derived from a delicate balance between the two metals on the surface of the nanoparticles, where the relative ratio represents a fundamental ruling factor. 


\begin{tabular}{|c|c|c|c|c|c|c|c|}
\hline Catalyst & $\begin{array}{l}\text { Initial activity }{ }^{[a]} \\
{\left[\mathrm{h}^{-1}\right]}\end{array}$ & GLY conv. [\%] (at 3h) & Glyceric & Tartronic & Glycolic & Formic & Oxalic \\
\hline $1 \% \mathrm{Au} / \mathrm{TiO}_{2}$ SOL_calc & 1662 & 90 & 64.0 & - & 4.0 & 6.3 & - \\
\hline $1 \% \mathrm{Au} / \mathrm{TiO}_{2} \mathrm{DPU}_{-}$fresh & - & - & - & - & - & - & - \\
\hline $1 \% \mathrm{Au} / \mathrm{TiO}_{2}$ DPP_red & 1679 & 85 & 56.0 & - & - & 10.0 & - \\
\hline $1 \% \mathrm{Au}_{4} \mathrm{Ag}_{1} / \mathrm{TiO}_{2} \mathrm{DPU}$ & - & - & - & - & - & - & - \\
\hline $1 \% \mathrm{Au}_{4} \mathrm{Ag}_{1} / \mathrm{TiO}_{2}$ DPU_calc & 2113 & 81.9 & 56.8 & 12.2 & 9.6 & 6.1 & 2.4 \\
\hline $1 \% \mathrm{Au}_{4} \mathrm{Ag}_{1} / \mathrm{TiO}_{2}$ DPU_red & 1524 & 86.4 & 51.3 & 17.7 & 5.2 & 2.9 & 4.0 \\
\hline $1 \% \mathrm{Au}_{4} \mathrm{Ag}_{1} / \mathrm{TiO}_{2} \mathrm{SOL}$ & 892 & 59.8 & 68.7 & 6.5 & 9.8 & 7.7 & 3.0 \\
\hline $1 \% \mathrm{Au}_{4} \mathrm{Ag}_{1} / \mathrm{TiO}_{2}$ SOL_calc & 1616 & 62.7 & 52.1 & 16.5 & 14.9 & 10.4 & 2.7 \\
\hline
\end{tabular}

Considering the initial activity (conversion at $15 \mathrm{~min}$ ) we observed that the most active catalyst was $1 \% \mathrm{Au}_{4} \mathrm{Ag}_{1} / \mathrm{TiO}_{2}$ DPU_calc $\left(2113 \mathrm{~h}^{-1}\right)$ followed by the SOL_calc $\left(1616 \mathrm{~h}^{-1}\right)$. In this latter case it should be noted that the almost double activity of SOL catalyst obtained by calcination of the fresh sample, cannot be ascribed only to the removal of the protective agent ${ }^{[29]}$ considering also the growing of the particle size due to the thermal treatment (Table 3). The enlargement of the particle size should reduce the activity thus playing an opposite role compared to the removal of PVA. Looking at reaction profiles (Figure 14) we could also note the similarities of the catalytic

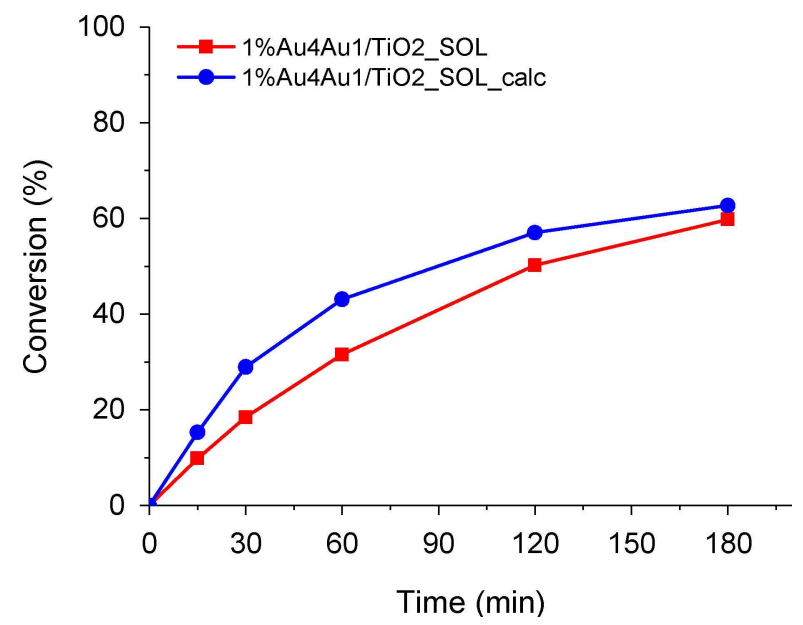

Figure 14. Glycerol conversion over time by $1 \% \mathrm{Au}-\mathrm{Ag}(4: 1)$ supported on $\mathrm{TiO}_{2}$ by SOL. Comparison between $1 \% \mathrm{Au}_{4} \mathrm{Ag}_{1} / \mathrm{TiO}_{2} \mathrm{SOL}$ as a) not treated (red squares), b) calcined (blue dots).

behaviour between fresh and calcined SOL sample being the conversion after $3 \mathrm{~h}$ quite similar regardless the presence of PVA and the particle size ( 2.4 vs $5.1 \mathrm{~nm}$ ). XPS revealed that calcination varied the surface composition which appeared slightly richer in Au (Table 3).

Also considering $1 \% \mathrm{Au}_{4} \mathrm{Au}_{1} / \mathrm{TiO}_{2}$ prepared by $\mathrm{DPU}$, the catalysts in both treated state (reduced and calcined) despite different initial activity behaved similarly (Figure 15) both showing a conversion of glycerol around $80 \%$ in $3 \mathrm{~h}$. The characterisation of the two catalysts by TEM and XPS appeared

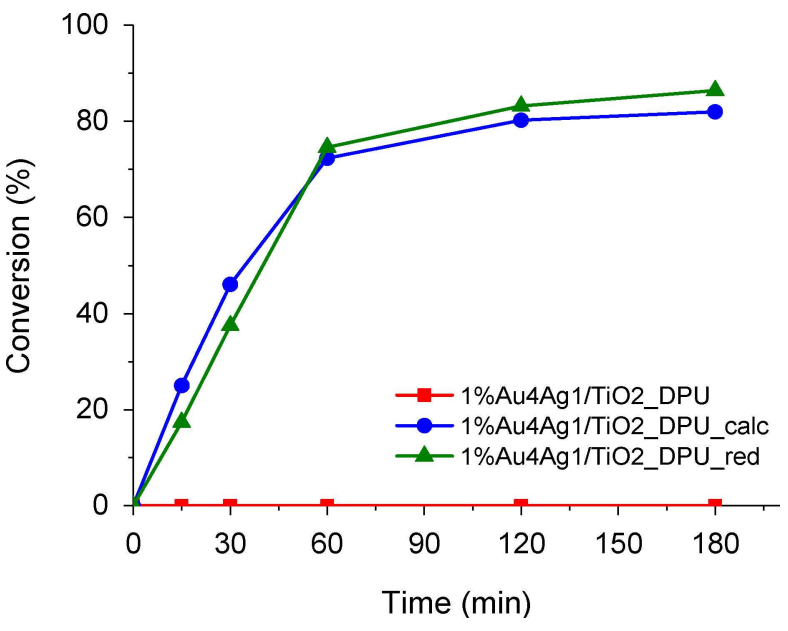

Figure 15 . Glycerol conversion over time by $1 \% \mathrm{Au}-\mathrm{Ag}(4: 1)$ supported on $\mathrm{TiO}_{2}$ by DPU. Comparison between a) not treated (red squares), b) calcined (blue dots) and c) reduced (green triangles).

very similar. The not treated as prepared state is inactive. As the thermal profile is the same, we thought that in this case the SMSI should be the same.

Comparing DPU and SOL synthesis, $1 \% \mathrm{Au}_{4} \mathrm{Ag}_{1} / \mathrm{TiO}_{2}$ by DPU were generally more active and reached higher glycerol conversion after $3 \mathrm{~h}$. From the selectivity point of view all the catalysts behaved similarly except for SOL derived sample that in the fresh form, where the protective agent is still present, showed a higher selectivity toward glyceric acid at the expense of tartronic acid. PVA in fact is known to be able to direct the adsorption-desorption of glycerol favouring the mono-oxidation. To be noted that Table 4 reported only the most relevant products. All the other minor products showed selectivity less than $10 \%$.

\section{Conclusion}

With the aim to study the ruling factor for developing synergism between $\mathrm{Au}$ and $\mathrm{Ag}$ in the selective glycerol oxidation, we prepared $1 \% \mathrm{AuAg} / \mathrm{TiO}_{2}$ at internal $\mathrm{Au}: \mathrm{Ag} 1: 1$ and $4: 1$ ratio by two different techniques namely DPU and SOL immobilisation. Both techniques present some peculiarities: 
DPU use a sequential deposition where $\mathrm{Ag}$ is deposited on the support first and then $\mathrm{Au}$ is added whereas SOL immobilisation technique forms the metallic particles in solution (avoiding $\mathrm{AgCl}$ precipitation) and then supporting them. The results highlighted different starting materials, the one (DPU) with markedly higher $\mathrm{Au} / \mathrm{Ag}$ atomic ratio at the surface than the other (SOL). We studied the evolution of the systems by thermal treatment in different atmosphere $\left(\mathrm{H}_{2}\right.$ and air). In the case of SOL samples we observed sintering during calcination with an increase of particle size from $2.7 / 2.9 \mathrm{~nm}$ to $5.3 / 5.1 \mathrm{~nm}$ depending on the $\mathrm{Au} / \mathrm{Ag}$ ratio. The particle size of thermally treated DPU samples were $2.6 / 2.4 \mathrm{~nm}$. UV-vis, XPS and CO-DRIFT have been carried out highlighting quite surprising similarities between calcined and reduced samples. In particular, it seems that thermal treatment induced the establishing of SMSI which become the ruling factor determining the oxidation state of the metal. The $1 \% \mathrm{Au}_{4} \mathrm{Ag}_{1} / \mathrm{TiO}_{2}$ DPU both reduced and calcined presented almost the same distribution of metals with the same oxidation state.

Correlating the catalytic behaviour and the characterization performed to the catalysts we could conclude that the ratio between $\mathrm{Au}$ and $\mathrm{Ag}$ on the surface of the particles is fundamental for developing a synergistic effect. In fact, all the catalysts tested with an internal ratio of $1: 1$ resulted inactive. In particular, the composition of the catalyst should be always gold-rich. The presence of larger amount of Au compared to $\mathrm{Ag}$, allows the $\mathrm{Ag}$ to be more stable in the reduced form even in an oxidative environment. The particle size does not appear very important at least in the range here investigated $(2-5 \mathrm{~nm})$ while more relevant appeared the exposure of the metals, being the gold preferred. Moreover, the synergy between Au and $\mathrm{Ag}$ can be also mediated by the presence of $\mathrm{Au}^{\delta+}$ which can be always formed through the interaction with the support.

\section{Acknowledgements}

We want to thank Viridiana Maturano for DPU samples preparation. RZ thanks DGAPA-UNAM IN103719 project for financial support.

\section{Conflict of Interest}

The authors declare no conflict of interest.

Keywords: AuAg bimetallic catalyst - synergistic effect glycerol oxidation
[1] Z. Bhushan N. H. David, D. N. Matthew, D. Robert, Science 2010, 330, 7478.

[2] P. Gallezot, Catal. Today 1997, 37, 405-418.

[3] A. Behr, J. Eilting, K. Irawadi, J. Leschinski, F. Lindner, Green Chem. 2008, $10,13-30$.

[4] C. H. Zhou, J. N. Beltramini, Y. X. Fan, G. Q. Lu, Chem. Soc. Rev. 2008, 37, 527-549.

[5] S. Carrettin, P. McMorn, P. Johnston, K. Griffin, C. J. Kiely, G. J. Hutchings, Phys. Chem. Chem. Phys. 2003, 5, 1329-1336.

[6] F. Porta, L. Prati, J. Catal. 2004, 224, 397-403.

[7] S. E. Davis, M. S. Ide, R. J. Davis, Green Chem. 2013, 15, 17-45.

[8] P. Konova, A. Naydenov, C. Venkov, D. Mehandjiev, D. Andreeva, T. Tabakova, J. Mol. Catal. A Chem. 2004, 213, 235-240.

[9] F. Yang, M. S. Chen, D. W. Goodman, J. Phys. Chem. C 2009, 113, 254260.

[10] D. E. Starr, S. K. Shaikhutdinov, H.-J. Freund, Top. Catal. 2005, 36, 33-41.

[11] A. J. Wang, X. F. Zhang, L. Y. Jiang, L. Zhang, J. J. Feng, ChemCatChem 2018, 10, 3319-3326.

[12] X.-Y. Huang, A.-J. Wang, X.-F. Zhang, L. Zhang, J.-J. Feng, ACS Appl. Energy Mater. 2018, 1, 5779-5786.

[13] Y. C. Shi, J. J. Feng, X. X. Lin, L. Zhang, J. Yuan, Q. L. Zhang, A. J. Wang, Electrochim. Acta 2019, 293, 504-513.

[14] H. You, Z. Wu, Y. Jia, X. Xu, Y. Xia, Z. Han, Y. Wang, Chemosphere 2017, $183,528-535$.

[15] C. Louis, Catalysts 2016, 6, 110.

[16] J.-H. Liu, A.-Q. Wang, Y.-S. Chi, H.-P. Lin, C.-Y. Mou, J. Phys. Chem. B 2005, 109, 40-43.

[17] A. Sandoval, A. Aguilar, C. Louis, A. Traverse, R. Zanella, J. Catal. 2011, $281,40-49$.

[18] T. Yonezawa, N. Toshima, New J. Chem. 1998, 22, 1179-1201.

[19] L. Deng, W. Hu, H. Deng, S. Xiao, J. Tang, J. Phys. Chem. C 2011, 115, 11355-11363.

[20] T. J. A. Slater, A. Macedo, S. L. M. Schroeder, M. G. Burke, P. O'Brien, P. H. C. Camargo, S. J. Haigh, Nano Lett. 2014, 14, 1921-1926.

[21] C. Méthivier, R. Zanella, C. Louis, L. Delannoy, A. Sandoval, Appl. Catal. A 2015, 504, 287-294.

[22] F. Somodi, L. Prati, A. Balerna, C. Evangelisti, A. Beck, A. Villa, G. Nagy, C. Tiozzo, A. Jouve, J. Catal. 2018, 368, 324-335.

[23] T. Benkó, A. Beck, K. Frey, D. F. Srankó, O. Geszti, G. Sáfrán, B. Maróti, Z. Schay, Appl. Catal. A 2014, 479, 103-111.

[24] R. Zanella, L. Delannoy, C. Louis, Mechanism of Deposition of Gold Precursors onto TiO2 during the Preparation by Cation Adsorption and Deposition-precipitation with $\mathrm{NaOH}$ and Urea, 2005.

[25] R. Zanella, C. Louis, Catal. Today 2005, 107-108, 768-777.

[26] F. Bonaccorso, M. Zerbetto, A. C. Ferrari, V. Amendola, J. Phys. Chem. C 2013, 117, 13217-13229.

[27] A. M. Ferraria, A. P. Carapeto, A. M. Botelho do Rego, Vacuum 2012, 86, 1988-1991.

[28] K. H. Hr. Klimev, K. Fajerwerg, K. Chakarova, L. Delannoy, C. Louis, J. Mater. Sci. 2007, 42, 3299-3306.

[29] S. Campisi, C. E. Chan-Thaw, D. Wang, A. Villa, L. Prati, Catal. Today 2016, 278, 91-96.

Manuscript received: April 1, 2019

Revised manuscript received: May 14, 2019

Accepted manuscript online: May 16, 2019

Version of record online: June 12, 2019 